\section{Modified technique of endocapsular lens aspiration for severely subluxated lenses}

\begin{abstract}
Purpose Severely subluxated crystalline lenses pose a difficult situation to anterior segment surgeons and can only be managed surgically by removal of the lens as well as the capsular bag. Several techniques have been described in literature for the management of such cases. We describe a modified technique of endocapsular lens aspiration by the limbal route for lens extraction through small incisions on the cornea.
\end{abstract}

Patients and methods Thirty-two eyes of $\mathbf{1 6}$ consecutive patients with severely subluxated crystalline lenses were recruited in the study. All eyes underwent a modified technique of lens aspiration within the capsular bag using a single instrument, vitrectomy cutter, and irrigation cannula, followed by sacrificing of the capsular bag. The patients were either left aphakic or implanted with an open loop anterior chamber intraocular lens (ACIOL

Department of Ophthalmology, Cataract and Refractive Surgery Services, Dr Rajendra Prasad Centre for Ophthalmic Sciences, All India Institute of Medical Sciences, New Delhi, India

Correspondence: S Khokhar, Department of Ophthalmology, Cataract and Refractive Surgery Services, Dr Rajendra Prasad Centre for Ophthalmic Sciences, All India Institute of Medical Sciences, New Delhi 110029, India

Tel: +91 11 26593073;

Fax: +911126852919.

E-mail: skhokhar38@yahoo. com

Received: 9 October 2016 Accepted in revised form: 21 June 2017

Published online:

11 August 2017
Kelman Multiflex) and prospectively followed up for a period of 3 months.

Results The mean age of the patients was 9 years 3 months \pm 3 years (range 5-15 yrs). All eyes underwent complete lens aspiration within the capsular bag with no dislocation of the lens matter. ACIOL was inserted in 22 eyes $(68.7 \%)$ and 10 eyes $(31.2 \%)$ were left aphakic. All the surgeries were uneventful. The mean best corrected visual acuity (BCVA) at 3 months post surgery was $0.47 \pm 0.11$ $\log$ MAR which was significantly better than pre-operative BCVA $(P=0.001)$. The percentage endothelial cell loss at 3 months was $7.1 \%$. There was no evidence of glaucoma, corneal decompensation, or retinal detachment. The astigmatism which increased from $1.45 \mathrm{D} \pm 086$ preoperatively to $3.76 \mathrm{D} \pm 2.021$ week post-operatively due to sutures reduced to $1.97 \mathrm{D} \pm 0.81$ post suture removal at 3 months.

Conclusion The modified technique of endocapsular lens aspiration proves to be a
S Khokhar, N Aron, N Yadav, G Pillay and E Agarwal

simple and effective method of removal of the lens-capsular bag complex in severely subluxated lenses.

Eye (2018) 32, 128-135; doi:10.1038/eye.2017.160; published online 11 August 2017

\section{Introduction}

Subluxated lens or ectopia lentis is not a very infrequent finding that comes across the anterior segment surgeons today. Nonetheless, an appropriate surgical management of ectopia lentis is a daunting task. Milder degrees of subluxation can be treated non-surgically or with capsular support devices with phacoemulsification and in the bag implantation of intraocular lens (IOL). ${ }^{1}$ However, in severe cases of subluxation, especially cases with more than 9 clock hours of subluxation, it is difficult to salvage the capsular bag and hence needs to be sacrificed to clear the visual axis. Historically, intracapsular cataract extraction (ICCE) was performed for cases with severely subluxated crystalline lenses with a large incision. With the advancement in technology and

instrumentation, there has been a trend towards micro-incision surgeries which can be successfully implemented in complex situations including subluxated lenses. This especially holds importance as large incision to deliver the lens leads to vitreous disturbances which may cause retinal detachment post surgery. Further, the visual rehabilitation of these patients without capsular support is not an easy task as compared to patients wherein a capsular or sulcus supoort is present for the placement of IOL either in the bag or sulcus. Again, out of the varied IOLs available in the market with placement at different positions in the eye, a careful selection needs to be done in children keepng in mind the long term safety. We herein describe a modified technique of endocapsular lens aspiration with lens capsule removal through small incisions at 
the limbus for severely subluxated crystalline lenses in pediatric population with or without placement of an IOL wherever feasible.

\section{Materials and methods}

All cases of non-traumatic severely subluxated lenses in the age group of 5-15 years were recruited from the Outpatient department and Lens Clinic Services of Dr Rajendra Prasad Centre for Ophthalmic Sciences, a tertiary eye center. The study was prospective and interventional in nature under general anesthesia and the study protocol adhered to the tenets of the Declaration of Helsinki. Written informed consent was obtained from the guardian of each patient. All cases with nuclear sclerosis more than grade 1 (Lens Opacification Classification System III), previous intraocular surgery, concurrent ocular pathology such as uveitis, glaucoma, high myopia, buphthalmos, presence of corneal opacity, and those unwilling for follow-up were excluded from the study. Institutional ethics committee approval was obtained.

\section{Pre-operative assessment}

All patients underwent a complete ophthalmic examination including pre-operative uncorrected distance visual acuity, corrected distance visual acuity (CDVA), slit lamp evaluation to determine the clarity of cornea, the extent of subluxation, and presence of cataract and noncontact tonometry to determine the intraocular pressure (IOP) and central corneal thickness (CCT). Non-contact specular microscopy (SP 3000P, Topcon Medical Systems, Inc., Oakland, NJ, USA) was performed to determine the endothelial cell count. Retinal evaluation with peripheral screening was done with the help of indirect ophthalmoscopy to rule out any treatable lesions especially in cases of longer axial lengths. Pre-operative biometry (axial length and keratometry) was performed using IOL Master 500 (Carl Zeiss Meditech, Germany). Immersion axial length was performed in cases where the IOL Master could not obtain the readings due to media opacity. White to white (W-W) and anterior chamber depth was done for all patients using the IOL Master 500 to accurately determine the appropriate size and feasibility of insertion of anterior chamber IOLs (ACIOL). All patients were started on prophylactic topical antibiotics (Moxifloxacin 0.5\%, Vigamox, Alcon Laboratories, Fort Worth, TX, USA) three times a day starting 3 days before the surgery. Topical homatropine bromide $2 \%$ (Homide, Indoco Remedies) was started 1 day before the surgery to maintain intraoperative pupillary dilatation.

\section{Surgical technique}

Endocapsular lens aspiration with lens capsule removal was performed in 32 eyes of 16 consecutive patients with severely subluxated crystalline lenses. All patients were operated by the same surgeon (SK) under general anesthesia. The lenses were either subluxated superiorly, superotemporally, or anterior subluxation in cases of spherophakias. Two small clear corneal incisions were made with the help of $23 \mathrm{~g}$ microvitreoretinal blade (MVR; Alcon Laboratories, Inc.) with a width of $0.9 \mathrm{~mm}$ at 10 o'clock and 2 o'clock position at the limbus with further insertion of the tip of the blade into the anterior capsule of the lens. Hence, two small nicks were created in the anterior capsule at the same time of making the corneal incisions. Following this, a viscodispersive agent (Viscoat; Alcon Laboratories, Inc.) was injected at the site from where the lens was displaced from its position to prevent anterior movement of the vitreous. Intracameral adrenaline $0.1 \mathrm{ml}$ of $1: 100000$ solution was injected to ensure complete dilatation of the pupil. Balanced salt solution (BSS) was injected through one or both the nicks between the lens matter and the caspule to ensure a slow but complete hydrodissection. No additional ophthalmic viscosurgical device was injected. This was followed by introduction of a vitrectomy cutter on Centurion system (25 G, Alcon Laboratories, Inc.) through one incision and a $27 \mathrm{~g}$ irrigation cannula through the other within the capsular bag to hold the capsular bag-lens complex in place. The vitrectomy cutter was kept in irrigationaspiration cut (I-A cut) mode and the lens matter was aspirated keeping vacuum at $400 \mathrm{~mm} \mathrm{Hg}$, aspiration flow rate at $50 \mathrm{cc} / \mathrm{min}$, cut rate at $100 \mathrm{cpm}$ and IOP at $55 \mathrm{~mm} \mathrm{Hg}$. After complete aspiration of the lens matter, the capsular bag was sacrificed keeping the vitrectomy cutter in the conventional anterior vitrectomy mode (CutIA) with vacuum at $250 \mathrm{~mm} \mathrm{Hg}$, aspiration flow rate at $20 \mathrm{cc} / \mathrm{min}$, cut rate at $4000 \mathrm{cpm}$ and IOP at $55 \mathrm{~mm} \mathrm{Hg}$. Limited anterior vitrectomy was then performed keeping the cutter in cut I-A mode to ensure that the anterior chamber was free of vitreous strands if any. Viscoelastic if present in the anterior chamber was removed with vitrectomy cutter itself. Intracameral pilocarpine $0.5 \%$ (Carpinol, Sunways Pvt. Ltd., Mumbai, Maharashtra, India) was injected through one of the limbal incisions to ensure a round pupil. Gentle stroking of the iris was done with Sinskey hook to facilitate pupillary constriction. A peripheral iridotomy was made superiorly with the help of vitrectomy cutter in I-A cut mode. The two corneal incisions were hydrated with BSS and left sutureless.

Following the aspiration of lens matter and sacrificing the capsular bag, the limbal incision was enlarged to $6 \mathrm{~mm}$ incision size. Sterile air was injected into the anterior chamber. A Kelman Multiflex Anterior Chamber 
Intraocular Lens (ACIOL, available in sizes of 12.5 and $13 \mathrm{~mm}$ ) was inserted with the help of McPherson forceps. The incision was then closed with the help of a single cross mattress suture. Air was removed and the incision was hydrated to form the anterior chamber. Cases where the white-white diameter was less than $9 \mathrm{~mm}$ or more than $12.5 \mathrm{~mm}$ and axial length was less than $17 \mathrm{~mm}$ were left aphakic due to non-availablity of the appropriate size and power of the ACIOL in these cases. Figure 1 and Supplementary Video depict the surgical steps of modified endocapsular lens aspiration in a patient of Marfan's syndrome with ectopia lentis with insertion of ACIOL.

\section{Post-operative protocol}

Postoperatively, the patients were administered topical moxifloxacin $0.5 \%$ (Vigamox, Alcon Laboratories) four times a day, topical prednisolone phosphate 1\% (P-lone, Syntho Pharmaceuticals, Lucknow, Uttar Pradesh, India) six times a day which was tapered on subsequent followups and a short acting cycloplegic such as tropicamide $1 \%$ (Auromide, Aurolabs, Madurai, Tamil Nadu, India) at night time. Those patients who were left aphakic were prescribed spectacles or contact lenses on follow-up after removal of the suture at main incision at 4 weeks followup. A psudophakic refraction was done for the patients implanted with ACIOL and a distance refractive correction with near add was given in the form of executive bifocal spectacles. The patients were followed up at day 1, 1 week, 1 month and 3 months post-operatively. At all follow-ups, UCVA, CDVA, IOP, $\mathrm{CCT}$, and specular microscopy was done to evaluate the ocular status. Slit lamp examination was done to look for the presence of corneal edema, stability of IOL and the patency of iridotomy.

\section{Statistical analysis}

The data were analyzed using SPSS for Windows software (version 20.0, International Business Machines Corp., Armonk, NY, USA). Data normality and Gaussian distribution were assessed using histograms. The mean, median, and SD data of each variable were calculated, A comparison of data over each follow-up was done using Repeated Measures ANOVA with Bonferroni adjustment for parametric variables. Non-parametric data was analyzed with Friedman test. The level of statistical significance was kept at a $P$-value $<0.05$.

\section{Results}

Thirty-two eyes of 16 patients underwent modified endocapsular lens aspiration with lens capsule removal for non-traumatic severely subluxated crystalline lenses (Table 1). Out of 16 patients, 9 patients $(56.2 \%, 9 / 16)$ were diagnosed as having Marfan's syndrome, 4 patients $(25 \%$, $4 / 16)$ had a marfanoid habitus, and 3 patients $(18.7 \%$, 3/16) had bilateral microspherophakia with anterior subluxation of lens. The mean age of the patients was
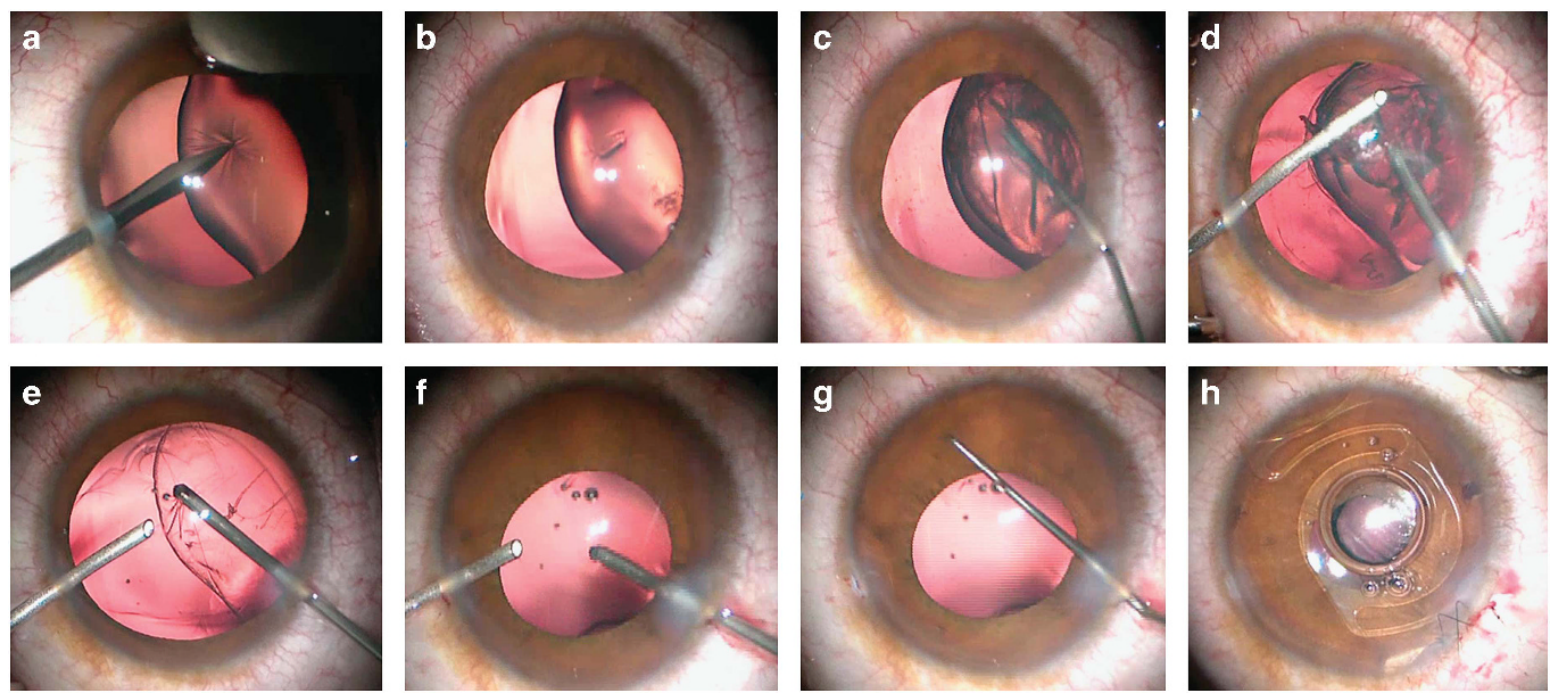

Figure 1 Modified technique of endocapsular lens aspiration with insertion of ACIOL in a case of Marfan's syndrome (a) MVR entry is made in the cornea and extended to make a nick in the anterior capsule of the lens, (b) two nicks are made in the anterior capsule with MVR blade, (c) BSS is injected through one of the nicks for hydrodissection (d) $25 \mathrm{~g}$ vitrectomy cutter is inserted through one of the nicks and irrigation cannula through the other and lens is aspirated in I-A cut mode, (e) capsular bag is eaten with vitrectomy cutter in I-A cut mode, (f) anterior vitrectomy is done with the cutter in conventional vitrectomy mode (g), Pilocarpine is injected intracamerally and iris is stroked with Sinkey hook to constrict the pupil, and (h) one of the corneal incisions is enlarged for the insertion of ACIOL and a peripheral iridotomy is done. 


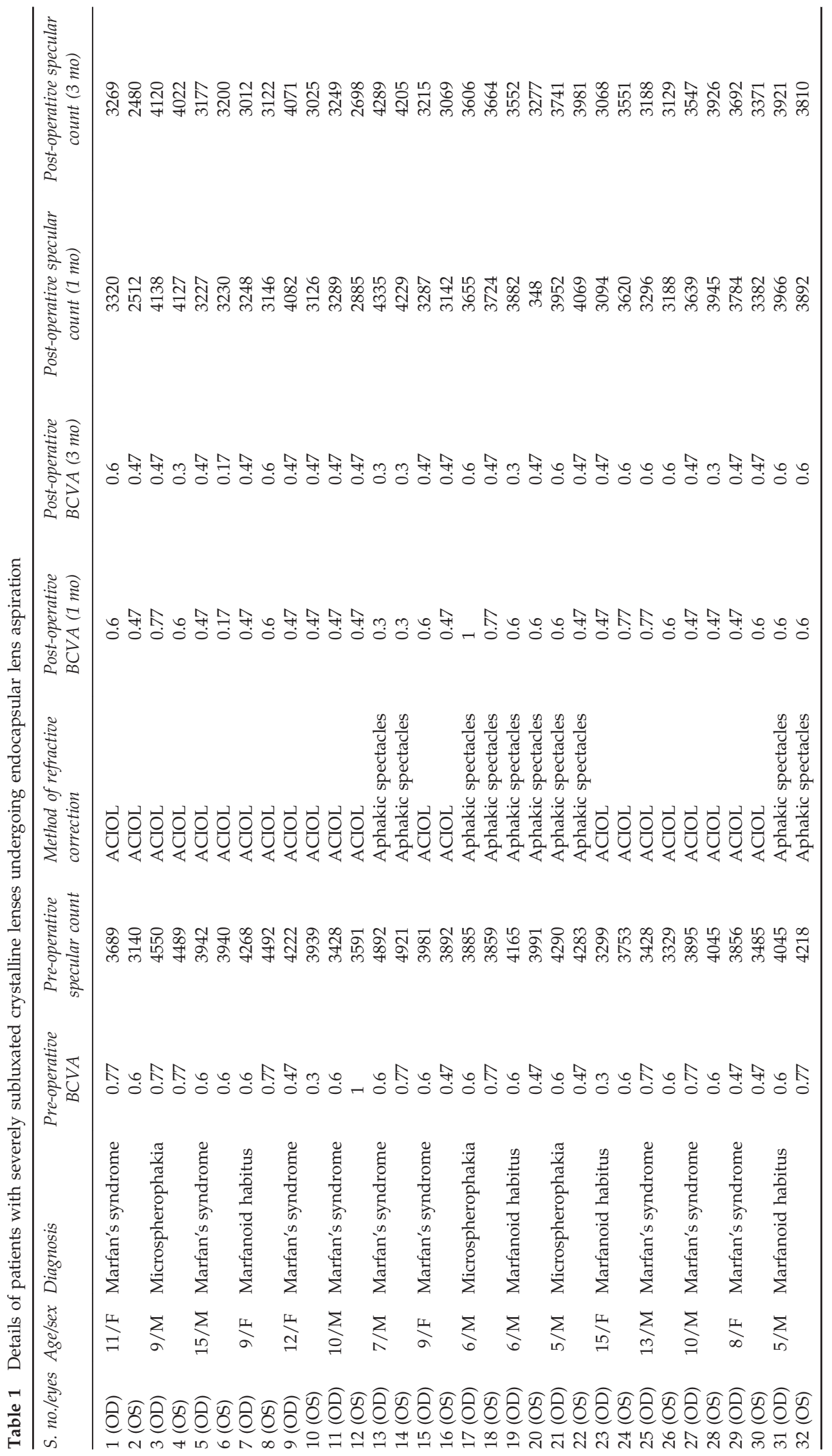


$9.375 \pm 3.16$ years (range $5-15$ years). The pre-operative UCVA of the patients was $1.3 \pm 0.36$ logarithm of minimum angle of resolution (logMAR) and the BCVA was $0.6 \pm 0.14$ on $\log$ MAR scale. The mean pre-operative endothelial cell count of the patients was 3775. \pm 407.5 cells $/ \mathrm{mm}^{2}$. The mean baseline IOP was $15.72 \pm 4.4 \mathrm{~mm} \mathrm{Hg}$ and mean CCT was $528.8 \pm 44.11 \mathrm{~mm} \mathrm{Hg}$. The mean pre-operative $\mathrm{W}-\mathrm{W}$ diameter was $11.87 \pm 0.57 \mathrm{~mm}$.

All eyes underwent complete bimanual lens aspiration within the capsular bag with the help of vitrectomy cutter. No posterior dislocation of the lens matter was noted in any of the cases. Limited anterior vitrectomy was done in all the cases in the pupillary plane. No forward movement of the vitreous was noted while performing in the bag aspiration of lens. All surgeries were uneventful. ACIOL were inserted safely in 22 eyes and 10 eyes were left aphakic. Out of these 10 eyes, 8 eyes had a large $\mathrm{W}-\mathrm{W}$ diameter $(>12.5 \mathrm{~mm}$ ) in which the ACIOL if placed may be small for the eye resulting in undue mobililty. The rest of the 2 eyes of the same patient had microspherophakia out of which one eye had an anterior dislocated lens with pupillary block glaucoma $(\mathrm{IOP}=30 \mathrm{~mm} \mathrm{Hg})$ and corneal edema $(\mathrm{CCT}=640 \mu \mathrm{m})$, thus best left aphakic at the time of surgery.

\section{Visual outcomes}

The BCVA at the end of 1 week was $0.66 \pm 0.21 \log$ MAR which improved to $0.55 \pm 0.15 \log \mathrm{MAR}$ at 1 month and $0.47 \pm 0.11 \log$ MAR at 3 months after surgery with a significant improvement as compared to pre-operative BCVA $(P=0.001)$ and BCVA at 1 month $(p=0.006)$. The overall mean pre-operative spherical equivalent was $11.75 \pm 4.05 \mathrm{D}$. At 3 months, the mean post-operative spherical equivalent in eyes with ACIOL was $0.51 \pm 0.77$ $\mathrm{D}$ which was statistically significant $(P<0.001)$. The mean post-operative spherical equivalent at 3 months in eyes which were left aphakic was $6.92 \pm 0.91 \mathrm{D}$ which was significantly lower than pre-operative values $(P=0.004)$. Thus, the surgical removal of lens significantly reduced the mean refractive error of the eye in patients with ectopia lentis with and without IOL implantation.

\section{Endothelial cell loss}

The mean endothelial cell count at the end of 1 week, 1 month, and 3 months post surgery was $3736 \pm 407.03$ cells $/ \mathrm{mm}^{2}, 3596.66 \pm 391.27$ cells $/ \mathrm{mm}^{2}$, and $3505.16 \pm 400.35$ cells $/ \mathrm{mm}^{2}$ respectively. The mean endothelial cell loss at 3 months compared to preoperative levels was $269.6 \pm 151$ cells $/ \mathrm{mm}^{2}$ amounting to $7.1 \%$ endothelial cell loss over 3 months which was statistically significant $(P=0.001)$. This was attributed to the intraoperative endothelial cell loss during surgery and post-operative inflammation in the first few weeks after the surgery.

\section{Intraocular pressure and central corneal thickness}

The mean IOP at 1 week, 1 month, and 3 months post surgery was $16.19 \pm 3.74 \mathrm{~mm} \mathrm{Hg}, 15.5 \pm 3.46 \mathrm{~mm} \mathrm{Hg}$, and $15.41 \pm 3.13 \mathrm{~mm} \mathrm{Hg}$, respectively, which was statistically insignificant at each follow-up $(P>0.5)$. There was no IOP spike in any patient on post-operative follow-ups. One eye with microspherophakia presented with anterior dislocation of lens and pupillary block glaucoma with an IOP of $30 \mathrm{~mm} \mathrm{Hg}$ which returned to normal on day 1 post operatively with endocapsular lens aspiration.

The mean CCT at 1 week, 1 month, and 3 months post surgery were $525.3 \pm 39.61 \mu \mathrm{m}, 526.8 \pm 39.43 \mu \mathrm{m}$, and $526.5 \pm 39.17 \mu \mathrm{m}$ with no significant difference from preoperative values. The eye with microspherophakia and high IOP at presentation presented with diffuse corneal edema with a CCT of $640 \mu \mathrm{m}$ which returned to $564 \mu \mathrm{m}$ at the end of 1 week with lens extraction. There were no cases of increased post-operative inflammation as seen on examination of anterior chamber cells/flare on slit lamp examination, measurement of IOP and CCT on sequential follow-ups. Post-operative retinal evaluation was done at 1 month and 3 months. No cases of retinal detachment or post-operative breaks were noted on any follow-up.

The astigmatism increased from $1.45 \mathrm{D} \pm 086$ preoperatively to $3.76 \mathrm{D} \pm 2.02$ one week post-operatively due to sutures reduced to $1.97 \mathrm{D} \pm 0.81$ post suture removal at 3 months. This suture and wound related astigmatism was comparable to pre-operative values.

\section{Discussion}

Surgical management of ectopia lentis with removal of lens and capsule through two small incisions without causing vitreous disturbances is a challenging task. Cases which present with severe forms of subluxation of more than $270^{\circ}$ zonulolysis, progressive causes of subluxation such as Marfan's syndrome and anterior dislocation of lens in microspherophakia cannot be managed with capsular support rings and in the bag placement of IOL. Such cases require complete capsular bag removal with or without placement of an IOL. One of the easiest methods of lens removal consisted of ICCE through a $6 \mathrm{~mm}$ incision at the corneoscleral limbus. However, this technique led to vitreous traction due to loss of posterior chamber leading to anterior movement of vitreous resulting in a higher risk of retinal detachment. ${ }^{2}$ Patients of Marfan's syndrome with axial myopia are already predisposed to retinal detachment and this technique posed a greater danger of retinal complications. Hence, 
the technique of intralenticular lens aspiration through a small incision came into practice in cases where capsular bag removal was deemed necessary.

The technique was first described in 10 cases of severe subluxation by Sinha et $\mathrm{al}^{3}$ wherein a bimanual irrigationaspiration was used followed by vitrectomy cutter to remove the capsular bag. In our technique we used the vitrectomy cutter and irrigation cannula alone wherein the lens matter was aspirated with the help of vitrectomy cutter itself in I-A cut mode followed by the removal of the bag and anterior vitrectomy using the same cutter. Hence, a single instrument was used for lens matter as well as capsular bag removal without the need for changing the instrument for both the procedures. Further in their technique, two small capsulorrhexis openings were made for the insertion of bimanual irrigationaspiration cannula for lens aspiration using Utrata capsulorrhexis forceps. This necessitated enlargement of the corneal incisions for the insertion of capsulorrhexis forceps. In our technique, two nicks were made in the anterior capsule of the lens with the help of a $23 \mathrm{~g}$ MVR (Alcon Laboratories) through which the vitrectomy cutter and irrigation cannula were inserted. Hence, this did not require enlargement of corneal incisions which remained at $0.9 \mathrm{~mm}$ width. Also, direct entry through the stab incisions without making two capsulorrhexis openings saved surgical time.

Viscodispersive agents such as Viscoat was used to coat the area of zonular dehiscence to compartmentalize the anterior chamber from the posterior chamber of the eye. This prevents both the anterior movement of the vitreous as well as drop of lens matter fibers posteriorly into the vitreous cavity. The placement of the irrigation cannula inside the capsular bag further reduced anterior chamber intraocular pressure fluctuations. This helped in reducing vitreo-retinal traction in such patients decreasing the risk of retinal complications in already compromised eyes.

It is advisable not to inject intracameral dye such as trypan blue in these cases since the dye migrates to the vitreous cavity through the area of zonular dehiscence reducing the visibility of the lens and capsular bag by retroillumination. This could lead to an inadvertent posterior capsular dehiscence with the vitrectomy cutter and a high risk of lens matter-capsular bag complex drop into the vitreous cavity.

In our series of cases, many eyes did not show brisk pupillary constriction with intracameral pilocarpine. All these patients were diagnosed to have Marfan's syndrome. The poor pupillary constriction in these cases could be attributed to the fact that a hypoplastic iris or ciliary muscle is present in these patients which causes decreases miosis and does not allow pilocarpine to show its full effect. ${ }^{4}$ Hence, we performed a gentle stroking of the iris with a Sinskey hook after injecting pilocarpine which facilitated constriction of the pupil for performing a peripheral iridotomy and insertion of an ACIOL.

Apart from the anterior route, various other techniques through small incisions have been described for in-toto removal of the subluxated capsular bag-lens complex. One of the most commonly used method is the removal of lens through the posterior route by pars plana lensectomy and anterior vitrectomy with or without the placement of IOL. ${ }^{5-8}$ It is already known that the incidence of retinal detachment increases after cataract surgery. The risk is further increased with younger age, male sex, and myopia which are invariably associated with Marfan's syndrome. ${ }^{9-11}$ The limbal or anterior route of surgery was preferable in our series of cases since it requires less instrumentation, and as already mentioned, it just required the use of a single instrument for aspiration of lens and capsular bag. Further, limited anterior vitrectomy without the insertion of a posterior infusion line can minimize the occurrence of trauma and vitreous traction to the vitreous base which can lead to retinal detachment. This has been strengthened by various reports of higher rates of intraoperative breaks and postoperative retinal detachment after pars plana lensectomy in Marfan's syndrome. ${ }^{12-14}$ Though a more complete anterior vitrectomy with or without posterior vitreous detachment can be performed through the pars plana approach, it does not reduce the risk of occurrence of retinal detachment, rather the incidence of intraoperative breaks increases which may lead to retinal detachment later. ${ }^{13}$ Since, in our series of cases, more than $80 \%$ patients were diagnosed to have Marfan's syndrome or had a marfanoid habitus, the preference of anterior route for surgery seemed plausible.

Yet another technique described for surgical management of ectopia lentis is femtosecond laser assisted cataract surgery with preservation of capsular bag and in the bag implantation of IOL. ${ }^{15,16}$ However, this technique of lens extraction was carried out in adults and no reports of its use in pediatric age group is available. Further, the femtosecond laser suite is generally situated away from the main operating room where the facilities for general anesthesia may not be present. Moreover, the patient needs to be shifted from the laser suite to the main operating room which in itself is a cumbersome task when the child is under general anesthesia. These limitations have restricted the use of femtosecond laser assisted cataract extraction in pediatric population.

This technique of endocapsular aspiration can be combined with an $\mathrm{ACIOL}^{17}$ or a glued IOL with intrascleral fixation of haptics ${ }^{18,19}$ wherein the scleral flaps are fashioned before the anterior chamber entry with MVR blade. Alternatively, an iris-claw lens (anterior fixation or retrofixation) can be placed depending upon the patient's age, surgeon expertize and $\mathrm{W}-\mathrm{W}$ diameter of 
the cornea. In cases with a $\mathrm{W}-\mathrm{W}$ diameter more than $13 \mathrm{~mm}$ such as buphthalmos, it is not advisable to place a scleral fixated or an ACIOL due to anticipated complications of slippage and instability respectively. Such cases can be managed with an iris-claw lens enclavated within the iris stroma. Though the insertion of ACIOL or iris-claw lens requires a large corneal incision, it is still preferred to carry out the lens removal by endocapsular lens aspiration through a small incision to avoid vitreous manipulations and subsequent retinal detachment.

Studies on scleral fixated IOL's in pediatric age group have shown a higher rate of vitreous hemorrhage and hyphema post implantation. ${ }^{19,20}$ Another risk associated with insertion of scleral fixated IOL (SFIOLs) is high risk of retinal detachment which is a devastating complication especially in cases of Marfan's syndrome with axial myopia. Retinal detachment was diagnosed in $4.9 \%$ of 122 eyes during a follow-up period of 42 months in adults. ${ }^{21}$ The Artisan iris-enclavated IOLs have been used on a very limited basis in pediatric patients with subluxated crystalline lenses with good short-term outcomes. ${ }^{22}$ Similarly, posterior chamber iris fixated IOLs have been used in children with ectopia lentis with good postoperative visual outcomes. ${ }^{23}$ However, the insertion and enclavation of these IOLs need surgical expertize and limits the mobility of iris. Further, there is invariably a risk of chronic endothelial cell loss, pigment dispersion and chances of IOL dislocation due to slippage with the iris fixated IOLs necessitating a second intervention within the pediatric eye. ${ }^{24}$

The modern generation ACIOL (Kelman Multiflex) have an open loop design with flexible haptics and a four point fixation in angle with minimal area of contact in the angle which have overcome the complications associated with older generation of ACIOLs such as pigment dispersion, glaucoma, and hyphema making them safer for use. ${ }^{25}$ Ravalico et al ${ }^{26}$ demonstrated that ACIOL implantation in adults did not appear to alter corneal endothelial function over a period of 5 years. Further, Morrison et $a l^{17}$ performed primary ACIOL (open loop) placement in pediatric eyes with Marfan's syndrome after pars plana lensectomy and vitrectomy with good postoperative outcomes and no intraoperative or postoperative complications.

In view of a majority of patients with Marfan's syndrome or Marfanoid habitus in our study with axial myopia, lower scleral rigidity and a predisposition for retinal detachment, we did not prefer to place SFIOL in our group of patients. ACIOLs were preferred over SFIOLs especially in our group of patients with deep anterior chambers thus preventing accelerated endothelial cell loss. Out of the anterior chamber lenses, we preferred to place angle supported IOLs rather than iris fixated
IOLs in view of ease of insertion and no risk of slippage and dislocation.

Our modified technique of endocapsular lens aspiration provides for a simple and effective way of removal of the lens-capsular bag complex through small incisions on the cornea. A well planned and expertly implanted ACIOL can re-emerge as alternative to SFIOL and iris-claw lens. The long term results will add the necessary impetus for ACIOLS to be used more frequently in practice specially for more than $270^{\circ}$ subluxation in children. This technique might make the management of severe subluxations facile with wider acceptability among the anterior segment surgeons across the globe.

\section{Summary}

What was known before

- Intralenticular lens aspiration has been described in literature for the surgical management of severely subluxated crystalline lenses in Marfans syndrome.

What this study adds

- A modified technique of endocapsular lens aspiration has been described which helps in aspiration of the lens matter and removal of the capsular bag through two small incisions and use of a single instrument which makes the procedure simpler and easier.

- This technique is useful not only in Marfan's syndrome but also other cases such as microspherophakia and homocystinuria.

\section{Conflict of interest}

The authors declare no conflict of interest.

\section{References}

1 Kim EJ, Berg JP, Weikert MP, Kong L, Hamill MB, Koch DD et al. Scleral-fixated capsular tension rings and segments for ectopia lentis in children. Am J Ophthalmol 2014; 158(5): 899-904.

2 Naeser K, Baggesen K, Knudsen EB. Retinal detachment following intracapsular cataract extraction. A 10-year follow-up study. Acta Ophthalmol Scand 1998; 76(6): 727-730.

3 Sinha R, Sharma N, Vajpayee RB. Intralenticular bimanual irrigation: aspiration for subluxated lens in Marfan's syndrome. J Cataract Refract Surg 2005; 31(7): 1283-1286.

4 De Paepe A, Devereux RB, Dietz HC, Hennekam RC, Pyeritz RE. Revised diagnostic criteria for the Marfan syndrome. Am J Med Genet 1996; 62: 417-426.

5 Shortt AJ, Lanigan B, O'Keefe M. Pars plana lensectomy for the management of ectopia lentis in children. J Pediatr Ophthalmol Strabismus 2004; 41: 289-294.

6 Miraldi Utz V, Coussa RG, Traboulsi EI. Surgical management of lens subluxation in Marfan syndrome. J AAPOS 2014; 18: 140-146.

7 Wu-Chen WY, Letson RD, Summers CG. Functional and structural outcomes following lensectomy for ectopia lentis. J AAPOS 2005; 9: 353-357. 
8 Hubbard AD, Charteris DG, Cooling RJ. Vitreolensectomy in Marfan's syndrome. Eye 1998; 12 (Pt 3a): 412-416.

9 Loewenstein A, Barequet IS, De Juan E, Maumenee IH. Retinal detachment in Marfan syndrome. Retina 2000; 20: 358-363.

10 Maumenee IH. The eye in the Marfan syndrome. Trans Am Ophthalmol Soc 1981; 79: 684-733.

11 Dotrelova D, Karel I, Clupkova E. Retinal detachment in Marfan's syndrome. Characteristics and surgical results. Retina 1997; 17: 390-396.

12 Fan F, Luo Y, Liu X, Lu Y, Zheng T. Risk factors for postoperative complications in lensectomy-vitrectomy with or without intraocular lens placement in ectopia lentis associated with Marfan syndrome. Br J Ophthalmol 2014; 98(10): 1338-1342.

13 Singh MS, Casswell EJ, Boukouvala S, Petrou P, Charteris DG. Pars plana vitrectomy and lensectomy for ectopia lentis with and without the induction of a posterior vitreous detachment. Retina; e-pub ahead of print 15 February 2017; doi:10.1097/IAE.0000000000001534.

14 Babu N, Muraly P, Ramasamy K. Twenty-three-gauge two-port pars plana lensectomy for the management of ectopia lentis in children. Retina 2010; 30(6): 971-974.

15 Chee SP, Wong MH, Jap A. Management of severely subluxated cataracts using femtosecond laser-assisted cataract surgery. Am J Ophthalmol 2017; 173: 7-15.

16 Crema AS, Walsh A, Yamane IS, Ventura BV, Santhiago MR. Femtosecond laser-assisted cataract surgery in patients with Marfan syndrome and subluxated lens. J Refract Surg 2015; 31(5): 338-341.

17 Morrison D, Sternberg P, Donahue S. Anterior chamber intraocular lens (ACIOL) placement after pars plana lensectomy in pediatric Marfan syndrome. J AAPOS 2005; 9(3): 240-242.

18 Kumar M, Arora R, Sanga L, Sota LD. Scleral-fixated intraocular lens implantation in unilateral aphakic children. Ophthalmology 1999; 106(11): 2184-2189.

19 Asadi R, Kheirkhah A. Long-term results of scleral fixation of posterior chamber intraocular lenses in children. Ophthalmology 2008; 115(1): 67-72.

20 Bardorf CM, Epley KD, Tychsen L. Pediatric transscleral sutured intraocular lenses: efficacy and safety in 43 eyes followed an average of 3 years. J AAPOS 2004; 8: 318-324.

21 Lee JG, Lee JH, Chung H. Factors contributing to retinal detachment after transscleral fixation of posterior chamber intraocular lenses. J Cataract Refract Surg 1998; 24: 697-702.

22 Lifshitz T, Levy J, Klemperer I. Artisan aphakic intraocular lens in children with subluxed crystalline lenses. J Cataract Refract Surg 2004; 30: 1977-1981.

23 Faria MY, Ferreira N, Neto E. Retropupillary iris-claw intraocular lens in ectopia lentis in Marfan syndrome. Int Med Case Rep J 2016; 9: 149-153.

24 Kopel AC, Carvounis PE, Hamill MB, Weikert MP, Holz ER. Iris-sutured intraocular lenses for ectopia lentis in children. J Cataract Refract Surg 2008; 34: 596-600.

25 Dick HB, Augustin AJ. Lens implant selection with absence of capsular support. Curr Opin Ophthalmol 2001; 12(1): $47-57$.

26 Ravalico G, Botteri E, Baccara F. Long-term endothelial changes after implantation of anterior chamber intraocular lenses in cataract surgery. J Cataract Refract Surg 2003; 29(10): 1918-1923.

Supplementary Information accompanies this paper on Eye website (http://www.nature.com/eye) 